\title{
On Structure and Semantics of Reflexive Constructions in English
}

\author{
Yelena Mkhitaryan ${ }^{1, *}$, Loretta Bazikyan ${ }^{2}$ \\ ${ }^{1}$ Faculty of Foreign languages, Kh. Abovyan Armenian State Pedagogical University, Armenia \\ ${ }^{2}$ Yerevan Brusov State University of Languages and Social Sciences, Armenia
}

Copyright $\mathrm{O} 2016$ by authors, all rights reserved. Authors agree that this article remains permanently open access under the terms of the Creative Commons Attribution License 4.0 International License

\begin{abstract}
Reflexive or self-pronouns make up inherent part of reflexive constructions in English. They have a dual function in the sentence: they are used as indicators of the category of reflexivity and as intensifiers used for emphasis. In both cases they express the relation between the participants of the event that refer to the same entity. But if in the first case this relation can be described as that of the subject and the object, the same cannot be said about intensifiers. The latter's role is limited by giving an extra force or importance to the element of the sentence it relates to. The aim of the present paper is to point out functional differences between these two uses of reflexive pronouns as well as to indicate specific structural and semantic features that they reveal in constructions they make part of. The study shows that constructions with reflexive pronouns functioning as indicators of reflexivity are diverse both semantically and structurally, in contrast to reflexives used for emphasis, whose primary function consists in intensification. Nevertheless, they too display some distinctive semantic and pragmatic meanings which depend on the situation and character of the accomplished action.
\end{abstract}

Keywords Reflexivity, Reflexive Pronoun, Emphatic Reflexive Pronoun, Dual Function, Intensifier, Coreference, Affectedness

\section{Introduction}

Reflexive or self-pronouns express the relation between the participants of the event that refer to the same entity. As $\mathrm{Ph}$. Payne notes "in most cases, reflexive pronouns indicate coreference between the performers of two roles filled by one entity" $(1,309)$. The same approach is expressed by R. Jacobs, who notes that reflexive pronouns have their antecedents to which they relate in the same minimal clause or noun phrase $(2,130-131)$. Reflexive pronouns have different functions in the sentence. They function as 1) indicators of the category of reflexivity or 2) intensifiers used for emphasis. In both cases they are coreferent with an element of the sentence they relate to.

It is worth mentioning that reflexive pronouns used in the second function are singled out by some linguists as a separate group entitled emphatic pronouns. (3,185-187; 4, $104 ; 5,46 ; 6,41-42 ; 7,246-247)$. G. Veikhman describes them as morphological homonyms to reflexive pronouns (5, 40-41). We think this kind of approach contradicts the accepted principles of classification of parts of speech which take into account not only the functional, but semantic and formal criteria. Semantically, reflexive and the so-called 'emphatic pronouns' show similarity, characterizing the same entity; morphologically, they are quite identical: they are both formed by adding self /selves to the possessive or personal pronoun in the objective case. We think functional differences do not make it plausible to consider them as a separate group of pronouns. Most linguists view this type of pronouns as indicators of the category of reflexivity, but meantime stressing their emphatic use in special cases $(8,104$; 9, 242-243). The so-called 'emphatic pronouns' don't enter the relationship with their antecedent as subject and object like common reflexive pronouns. They are used as intensifiers, therefore their function is limited by imparting a special emphasis to the element of the utterance they are coreferent with. This subgroup of reflexive pronouns is known as emphatic reflexive pronouns (further ERP) in contrast with the other group of these pronouns which we can name reflexive pronouns proper (further RPP). We will start our study with RPPs since they present more interest from the structural and semantic points of view.

\section{Reflexive Pronouns Proper}

\subsection{The Status of Reflexive Pronouns}

Constructions with reflexive pronouns have been a subject of a number of researches of which the most substantial works belong to Th. Payne (1), Ch. Kreidler (10), R. Jacobs (2), J. Lyons (11), B. Ilyish (13), etc. The first issue to be 
discussed in regard with RPPs is their status. In English reflexive pronouns proper are often referred to as voice forms or voice auxiliaries $(1,306 ; 12,383)$. Some linguists analyze RPPs in terms of structural dichotomy. Thus, B. Ilyish speaks of two approaches to the status of these pronouns: 1) they are auxiliaries of the voice form, 2) they are separate words functioning as direct objects (13,116-119). Naturally, in the deep structure both elements are present, but in the surface structure the second element does not usually find explicit expression. So we can have equally: to wash oneself = to wash, to dress oneself = to dress. However, they preserve their reflexive meaning in both cases. Therefore almost all linguists contend that these verbs retain the category of reflexivity irrespective of the presence or absence of the corresponding pronoun $(14,385-386 ; 12,383)$. Some linguists $(1 ; 10 ; 14 ; 5 ; 11)$ have given a thorough analysis of reflexive constructions used without the respective pronouns, pointing out their specific semantic meanings, therefore we will not expand on this point.

\subsection{Syntactic Relations between Reflexive Pronouns and Their Coreferents}

Syntactically the relation between reflexive pronouns and their coreferents can be qualified as the relation between the subject and the object respectively. Sentences containing a subject and an object are usually ranked among transitive clauses, but this approach is rather challenging in reference to reflexive constructions, since the action expressed by a transitive verb takes place within the same argument. And here the linguists' opinions differ as to the status of this kind of constructions. We adhere to the opinion of $\mathrm{P}$. Hopper and S. Thompson, who claim that reflexive constructions occupy an immediate status between one-argument and two-argument clauses $(15,277-278)$. The same view is expressed by the Armenian linguist H. Barseghyan, who holds that reflexive constructions cannot be qualified as active or passive, since they cannot have an outer object (16, 128-129).

\section{3. Character of Affectedness of the Object}

Our aim is to indicate the character of coreference of the object expressed by an RPP with the subject as well as to define the extent of affectedness of the reflexive object (further RO) as a result of the action performed by the subject, i.e.to show to what degree the action of the subject is reflected on the object.

2.3.1. We will start our study with the description of the character of coreference between the subject and the RO. The basic assumption is that the RO is coreferential with the subject. Consider the following sentences:

a. I force myself to wait until I've done breakfast for Trish and Eddie. (Kinsella 189)

b. She can take care of herself very well. (Lee 46) c. I not only believe in myself but have made countless other men believe in me too. (Carswell 146)

In the above examples $(\mathrm{a}, \mathrm{b})$ we observe a full coreference of the RO with the subject: I=myself; she= herself. As far as sentence (c) is concerned, we note that the first use of the verb believe occurs with the prepositional phrase in myself, whereas in the second case the same verb takes in me because it correlates not with the basic subject (I), but countless other men in the non-finite clause. This phenomenon is examined by A. Radford, who interprets this phenomenon by introducing the concept of local antecedent. Accordingly, he claims that the sentence is grammatically correct if the antecedent of the reflexive pronoun is contained within the same clause as the reflexive pronoun, otherwise the sentences cannot be considered correct (17, 92).

2.3.2. Now we will examine cases when the coreference of the RO with the subject is not expressed directly.

1) The reflexive pronoun may be coreferential with the implicit subject.

a. And there's only my wife and my children and myself - and the governess...(Fitzgerald 225)

b. Hopefully, he will enjoy his holidays as myself.

The possessive pronoun $m y$ in (a) is suggestive of the first person, therefore myself is in a coreferential relation with it. The coreferent for myself in (b) is situationally implied: the modal adverb hopefully indicates the speaker's attitude towards the utterance, therefore it is inherently associated with the first person (I).

2) The coreferent of the subject may occur in a different finite clause.

a. Himself a good carpenter, he discussed with them the efficiency of some tools for a moment in a quiet, personal, interested voice. (Fitzgerald 209)

b. Short of searching CERN's entire complex himself, Sylvie knew there was only one other way to get the director's attention. (Brown 125).

c. Oh, I know the sort you are: no mercy for yourself or anyone else. (Housman 255)

As the examples show, the ROs are coreferential with the subjects occurring in different clauses of the composite sentences.

3) The RPP may not be coreferential with the subject.

a. You would stand for the divine right of a Stuart and crush with all the curses of the church thedivine right of a man, an individual, myself..... (Ibsen 150)

b. Jason's father insisted on an immediate audience with the school headmaster, himself an old Yale. (Segal 15)

The above examples show non-reference of the RO with 
the subject: You $\neq$ myself; Jason's father $\neq$ himself.

4) When the subject and an RPP are in a predicate relation to each other, the sentence acquires a new connotation: to be in a normal state of health or not influenced by others.

a. Unusual for one so young, she had the courage to always be herself. (19)

b. She didn't seem quite herself. (OALD)

c. John needed space to be himself (OALD)

5) The reflexive pronoun itself (in idiomatic expressions) is coreferent with the predicative expressed by an abstract noun.

a. Later she remembered all the hours of the afternoon as happy - one of those uneventful times that seem at the moment only a link between past and future pleasure but turn out to have been the pleasure itself. (Fitzgerald 87)

b. The manager of the hotel is courtesy itself. (OALD)

2.3.3. The reflexive pronoun may be replaced by the personal pronoun in the objective case without any considerable semantic change of meaning. Consider the following sentence.

An old man like me, if I got an overcoat, what do I need? (Mankowitz 382)

This sentence could easily be transformed into " $A n$ old man like myself, If I got an overcoat, what do I need?" The difference may be explained by the fact that the reflexive pronoun ascribes more prominence, more social weight to the subject. In the original example the poor old man had no ground to feel himself a man of importance (he even couldn't pay for the overcoat he had ordered), therefore his use of unstressed $m e$ is quite justified.

According to R. Carter and M. McCarthy constructions with reflexive pronouns sound more polite than those with personal pronouns. Thus, the linguists claim that the utterance These holidays are designed for people like yourself, young, fancy-free and unattached indicates a greater politeness than These holidays are designed for people like you... $(14,385)$.

Certainly, there a kind of politeness implied in the first utterance, but we think that here more essential is probably the speaker's hinting (with some sort of flattery) at the high social status of the addressee, thus nudging him into taking a certain action.

\subsection{Forms and Extent of Affectedness}

Now we will examine the forms and extent of affectedness the $\mathrm{RO}$ is subjected as a result of the action expressed by a transitive verb. It is worth mentioning that the idea of affectedness of the object of a transitive verb was suggested by P. Hopper and S.Thompson. The linguists point out various characteristic features of the subject and object, which determine the scale of transitivity of the verb, the so-called parameters of scalar transitivity (15,153-155). Since in our case we deal with reflexive constructions, we will try to define the extent of reflexivity of the action, i.e.to find out in what way and to what degree the action of the subject affects the object. We can indicate the following forms of affectedness:

\subsubsection{Radical physical affect}

a. Are you afraid of falling down and killing yourself? (Ibsen 169)

b. I could have shot myself. (Fitzgerald 158)

As we see the actions described in the examples are of a destructive character, i.e. the subject annihilates the object (RO) to the full extent.

2.4.2. Change of position, state, appearance or other actions of everyday character

a. He lifted himself on the arms of his chair. (Brown 107)

b. I can remember how I stood waiting for you in the garden - holding all myself in my arms like a basket of flowers. (Fitzgerald 183)

c. Art Rossi poured himself a drink and thought... (Segal 10)

\subsubsection{Mental affect}

a. I can console myself with the reminder that the guy who plays ahead of me is no ordinary jock. (Segal 49)

b. I toil and plan and humiliate myself. (Carswell 143)

\subsubsection{Psychological affect}

a. I acknowledged to myself that I was not really as I maintained by her shortcomings and mistakes... (Heller 165 )

b. How could they do this to him-someone who had already distinguished himself in the college community? (Segal 73)

2.4.5. Moral affect

a. I have only myself to blame. (Fitzgerald 69)

b. I declare myself unsatisfied. (Fitzgerald 78)

\subsubsection{Zero affect}

In this case we observe a full confluence between the subject and the object.

a. She didn't seem quite herself. (OALD)

b. John needed space to be himself (OALD)

The identity may be based on fantasy or imagination:

- He fancied himself as a hypnotist. (Fitzgerald 147)

So we see that the extent of affectedness of the reflexive object ranges from radical physical changes to zero affect in which case the subject and the RO display complete 
emerging. Between these two extremes lie various actions of mental, psychological and moral character as well as actions of a minor physical nature that affect the RO this or another way.

\section{Emphatic Reflexive Pronouns}

\subsection{Position of ERP in the Sentence}

As we have already mentioned, emphatic reflexive pronouns (ERP) are used to accentuate the element of the utterance it is coreferent with. Like RPPs, they usually occur in the same clause as their antecedents. They are often found to follow immediately after their co-referent noun phrases. But as Biber et al. point out "A separation may be preferable because it agrees with the general tendency in English to place heavily stressed elements late in the clause (18, 344-345). Most linguists find that the position of the ERP in the sentence does not imply any substantial change of semantic meaning. Quirk and Greenbaum see almost no difference in the following emphatic sentences with a different position of reflexives $(8,104)$ :

a. I've never been there myself.

b. I myself have never been there.

c. I have never myself been there.

The same is observed by Leech and Svartvik, who find that John himself told me is equal to John told me himself as in both cases It was John, and no one else, who performed the action of telling $(9,166-167)$.

However, G. Veikhman sees some difference in the meanings of the following sentences.

a. The owner himself built the house.

b. The owner built the house himself.

According to Veikhman in (a) the idea is stressed that it is the owner who built the house, in (b) that he built the house alone, without anybody else's help $(5,41)$. We think it is difficult to discern any noticeable semantic difference between these two sentences.

\subsection{Semantic Meanings of the ERP}

The analysis of semantic meanings of ERPs allows us to say that they are used to indicate:

3.2.1. The subject of the action performs the action alone, without any help. The ERP is often used with all and (sometimes) by.

a. I live by myself. (OALD)

b. I painted the room all by myself. (OALD)

3.2.2. The subject's personal participation in the action or witnessing it personally.

a. - Those women I can understand exceedingly well.
-Oho! Perhaps you could do the same yourself?

- Why not? (Ibsen 145)

b. -I admit...that your wife is not particularly fond of this Miss Fosli.

-Is that all? I have noticed that myself. (Ibsen102)

c. And I wanted to see her myself.

(Miller371)

\subsubsection{Confirmation of the actualization of the action by a} certain person, so that to exclude any doubt or lack of trust or back the speaker's own statement.

a. You said yourself, only just now, that no one but I ought to be allowed to build. (Ibsen140)

b. Here he is now, you can ask him yourself. (Coward 286)

Often in such cases famous persons or professionals are quoted to give more weight and support to what the speaker is saying.

a. The doctor said it himself. (OALD)

b. Old Solomon himself couldn't make nothing by 'un. (Lee 52)

3.2.4. Actions take place in out of the ordinary, never thought of or expected manner, often used with the adverb even.

a. Part of George's duty was ...to find out what they really thought of Harvard, the seminar and - even Kissinger himself. (Segal 159).

b. They even made love one starry night in Harvard Yard itself in the quadrangle behind Sever Hall. (Segal 161)

Of special interest is the first example, in which the use of the dash before the proper noun makes the sense of unexpectedness stronger and more palpable.

\section{Conclusions}

Reflexive or self-pronouns make up inherent part of reflexive constructions in English. They have a double function in the sentence: they are used as indicators of the category of reflexivity and as intensifiers. However, in both cases they express the relation between the participants of the event that refer to the same entity. The relation between reflexive pronouns proper and their antecedents can be defined as that of the subject and the object. The study shows that reflexive pronouns proper used as objects are usually coreferent with the subject, though there are cases of noncoreference when the reflexive object is coreferent with other parts of the sentence and this entails some changes in the meaning of the sentence. The scale of reflexivity is defined by the extent of affectedness the object undergoes as a result of the action performed by the subject. The scope of affectedness of the object ranges from radical physical changes to zero affect, in which case the subject and the reflexive object display a complete confluence. Reflexive 
pronouns used for intensification display some distinctive semantic and pragmatic meanings which depend on the situation and character of the accomplished action.

\section{Fiction}

1. Brown D. Angels and Demons. London: A Random House Group Company, 2009.

2. Carswell D.Count Albany // 24 One-Act Plays selected by J. Hampden. London: J. M. Dent \& Sons LTD, 1964.

3. Coward N. Hands Across the Sea//24 One-Act Plays selected by J. Hampden. London: J. M. Dent \&Sons LTD, 1964.

4. Fitzgerald F.S. Tender Is the Night. Moscow: Raduga Publishers, 1983.

5. Heller J. Something Happened. New York: Dell Publishing Group, Inc.1974.

6. Ibsen H. The Master Builder// Six Great Modern Plays. New York: Dell Publishing Group, Inc.1967.

7. Kinsella S. The Undomestic Goddess. Transworld Publishers. 2006.

8. Lee Ch. Mr. Sampson //24 One-Act Plays selected by J. Hampden. London: J. M. Dent \&Sons LTD, 1964.

9. Mankowitz W. The Bespoke Overcoat//24 One-Act Plays selected by J. Hampden. London: J. M. Dent \&Sons LTD, 1964.

10. Miller A. All My Sons // Six Great Modern Plays. New York: Dell Publishing Group, Inc.1967.

11. Segal E. The Class. Bantam Books, Inc. 1985.

OALD $=$ Oxford Advanced Learner's Dictionary by A.S. Hornby, 2005.

\section{REFERENCES}

[1] Payne Th. (2011) Understanding English Grammar. Cambridge: Cambridge University Press.
[2] Jacobs R. (1995) English Syntax. A Grammar for English Language Professionals. Oxford University Press.

[3] Eastwood J. (1997) Oxford Guide to English Grammar. Oxford University Press.

[4] Gordon E. and I. Krylova (1986) A Grammar of Present-day English. Moscow: Higher School Publishing House.

[5] Veikhman G. (2002) Novoye v grammatike sovremennogo angliyskogo yazika Moscow: Astrel*Act.

[6] Tokmadjian H. (1995) A Modern English Grammar.Yerevan:Pyunik Publishing House.

[7] Kobrina et al. (2003) Theoretical Grammar of Modern English. Moscow: Visshaya Shkola.

[8] Quirk R. and S. Greenbaum (1978) A University Grammar of English. Longman.

[9] Leech J. and J. Svartvik (1983) A Communicative Grammar of English. Moscow: Prosveshcheniye.

[10] Kreidler Ch. W. (2002). Introducing English Semantics. New York: Routledge.

[11] Lyons J. (1978) Introduction to Theoretical linguistics. Moscow: Progress.

[12] Blokh M. (1983) A Course in Theoretical English Grammar. Moscow: Visshaya Shkola.

[13] Ilyish B. (1971) The Structure of Modern English .Leningrad: Prosvenshcheniye.

[14] Carter R. and M. McCarthy (2006) Cambridge Grammar of English. Cambridge: Cambridge University Press.

[15] Hopper P. and S. Thompson (1980). Transitivity in Grammar and Discourse// Language, \# 56.

[16] Barseghyan H. (1980) Study of parts of speech of the Armenian Language. Yerevan.

[17] Radford A. (2004) English Syntax. An Introduction. Cambridge University Press.

[18] Biber D., S. Johansson, G. Leech, S. Conrad, E. Finegan (2000) Grammar of Spoken and Written English. London: Longman.

[19] https//gma.com/georgia 